\title{
PERENCANAAN DAN PEMBUATAN MESIN POTONG KAYU
}

\author{
H. Midi ${ }^{1)}$, Rudi Siswanto2) \\ 1,2Program Studi Teknik Mesin \\ Fakultas Teknik Universitas Lambung Mangkurat \\ JL. Akhmad Yani Km.36 Banjarbaru, Kalimantan Selatan,70714 \\ Telp. 0511-4772646, Fax 0511-4772646 \\ E-mail : hmj745@gmail.com
}

\begin{abstract}
Main purpose of this final task is to design a wood cutter machine for channel saw on the wood board and to get the final result like a work sheet and to determine the machine component of the wood cutter until it's proper to built. This design of the modification wood cutter machine has some concept with some steps like: need, problem analysis and product specification, product concept design, analysis technique, modeling and the work sheet. the next process is build the wood cutter machine that has been planned. The final task result is a design that poured in the work sheet include the framework machine drawing, liner drawing, arm connector drawing, arm knife drawing, pen drawing, pivot transmission drawing, pivot eccentric drawing, circle eccentric drawing, puli and workspace drawing. The wood cutter capacity saw could reach $2 \mathrm{~cm}$ thickness. The machine booster resources is an electricity engine with $0.25 \mathrm{HP}$ power. The wood cutter from modification product dimension length $x$ wide $\times$ height that $350 \times 350 \times 910 \mathrm{~mm}$. the machine framework material use an iron steel profile $L 30 \times 30 \times 2 \mathrm{~mm}$ material St 42. The transmission pivot made from St 37 with dimension $015 \mathrm{~mm}$ and $300 \mathrm{~mm}$ length. The transmission system use belt component $V$ and two pair of Puli 1,5" and 3.5", work base board use Plywood. The final result of this design and the wood cutter making then will be built adjust the work sheet.
\end{abstract}

Keywords: planning, manufacture, wood cutting machine

\section{PENDAHULUAN}

Perkembangan teknologi setiap saat terus maju seiring perkembangan zaman, industri kayu kreatif pun juga tidak ketinggalan berkembang, dalam perkembangannya menuntut suatu hasil produk yang berkualitas, maka diperlukan proses pengerjaan yang efektif juga efisien. Penggunaan mesin gergaji dianggap mampu untuk mengikuti perkembangan zaman, sehingga bermunculan peralatan pemotongan kayu yang menggunakan penggerak mesin. Ukuran gergaji mesin relatif besar sehingga menyulitkan proses pemotongan kayu yang kecil dan beberapa jenis mesin yang ada tidak dapat digunakan untuk membuat alur ukir. Permasalahan itu disebabkan karena pemotongan sangat sulit untuk dikontrol pada saat melakukan pemotongan sesuai kebutuhan. Ukuran mesin gergaji yang besar juga menjadi perhatian karena menyulitkan pemindahan dari satu tempat ketempat tertentu. Demikian halnya untuk para pengrajin kayu kreatif baik pembuat hiasan dinding maupun ukiran-ukiran pada benda-benda yang memiliki nilai estetika tinggi. Dengan dimensi bahan yang dikerjakan relatif kecil, maka dibutuhkan mesin potong kayu yang efektif dan efisien demi menunjang kualitas produksi.

Semakin berkembangnya bentuk pekerjaan di industri kayu kreatif, pengerjaan pemotongan kayu menuntut adanya perbaikan mutu produksi, kepresisian toleransi 
dan masih terbatasnya mesin potong yang efisien, maka inovasi alat menjadi perhatian untuk kemajuan. Selain itu, alat potong manual dan/atau mesin yang telah ada memiliki keterbatasan dalam memproduksi barang serta hasil produksi yang kurang maksimal menjadi salah satu landasan pendukung untuk merancang mesin potong kayu baru.

Dalam pembuatan berbagai jenis pola ukiran para pekerja kreatif kayu masih banyak menggunakan peralatan manual. Sebagian pekerja sudah menggunakan gergaji mesin CNC untuk kayu, akan tetapi mesin tersebut memiliki harga yang fantastis. Oleh sebab itu diperlukan mesin potong kayu yang dapat digunakan untuk memotong lurus dan berbelok serta dapat menghaluskan permukaan dalam satu wadah tanpa harus mengeluarkan biaya yang sangat besar.

Dari beberapa pertimbangan di atas maka penulis merancang mesin gergaji kayu untuk menunjang industri kreatif mengikuti perkembangan zaman sehingga pengerjaan dapat efektif, efisien dan ekonomis dibandingkan dengan mesin serupa demi produk berkualitas dan nilai kepresisian serta toleransi yang tinggi. Dimensi mesin yang berukuran kecil diharapan mudah untuk dikontrol operator dan mudah dipindahkan serta mampu mengerjakan kayu yang berukuran kecil tidak lebih dari $50 \mathrm{~cm}^{2}$. Motor listrik yang digunakan tidak lebih dari 200 watt sebagai penggerak utama, sistem transmisi menggunakan V-belt. Daun gergaji dirancang terhubung dengan poros eksentrik hingga menghasilkan prinsip gerakan naik turun tanpa ada penyangga pada bagian atas agar operator dapat dengan leluasa mengubah arah potong pada saat membuat alur tanpa harus merasa terganggu pandangan. Pada mesin potong kayu juga akan ditambahkan amplas yang dapat dipasang dan dilepas pada saat tidak digunakan. Mesin ini diharapkan mampu meningkatkan kualitas dan kuantitas produksi para pengrajin kayu.

\section{Permesinan Kayu}

Permesinan kayu bertujuan untuk menghasilkan suatu dimensi dan bentuk yang kehendaki dengan teliti juga akurat dengan kualitas permukaan yang baik. Permesinan kayu melalui satu atau kombinasi operasi yaitu penggergajian, penyerutan, pembentukan, pengaluran, pembubutan, pengampelasan dan sebagainya.

Kualitas permesinan kayu ditentukan oleh kayu, operator dan mesin, serta interaksi dari ketiga faktor tersebut. Interaksi kayu dengan mesin merupakan orintasi potongan, interaksi kayu dengan operator merupakan perlakuan awal dan interaksi operator adalah penyetelan alat.

\section{Spesifikasi} berikut:

Adapun spesfikasi yang harus dipenuhi mesin potong kayu ini adalah sebagai

a. Dapat memotong papan kayu dengan tebal $2 \mathrm{~cm}$.

b. Dimensi mesin yang tidak terlalu besar.

c. Dapat mempercepat proses penggergajian dengan bentuk lekuk-lekukan.

d. Mudah dalam pengoperasiannya.

e. Kontruksi harus kuat.

f. Mudah perawatannya.

g. Suku cadang tersedia di pasaran dan mudah didapat.

h. Mudah dipindahkan dengan model rangka berdimensi kecil.

i. $\quad$ Fungsi mesin lebih dari mesin yang sudah ada di pasaran. 
j. Mesin aman digunakan.

\section{Analisis Morfologi Alat}

a. Secara teknis alat harus dapat dipertanggung jawabkan, dalam hal ini alat harus

1) Memiliki dimensi yang kecil sehingga mesin mudah dipindahkan.

2) Pengoperasiannya mudah agar memungkinkan digunakan oleh para pengrajin.

3) Nyaman digunakan karena tinggi meja setinggi pinggang rata-rata orang Indonesia.

b. Secara ekonomi menguntungkan, hal ini terkait pada :

1) Daya motor relatif kecil sehingga dapat menekan penggunaan listrik

2) Memiliki fungsi ganda selain digunakan untuk memotong, juga dapat digunakan untuk membuat lekuk-lekukan pada papan kayu dan menghaluskan permukaan potongan.

c. Secara sosial dapat diterima

Mesin potong kayu ini nantinya harus dapat diterima oleh masyarakat dan menggantikan mesin gergaji yang sudah ada di pasaran.

\section{Klasifikasi Mesin Potong Kayu}

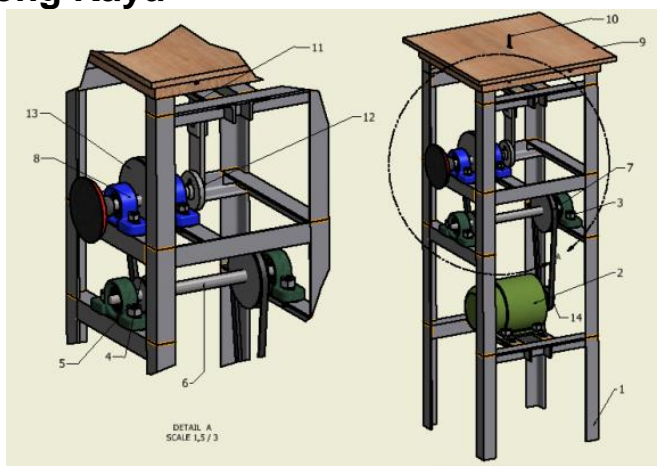

Gambar 1. Mesin Potong Kayu

Keterangan :

1 Rangka

2 Motor Listrik

3 Baut

4 Puli Kecil

Transmisi

5 Flange Bearing 12 Torak

6 Poros Transmisi 13 Puli Besar

7 V-Belt

Transmisi

14 Puli Motor

Langkah-langkah pengoperasian mesin antara lain :

1. Siapkan bahan berupa papan yang sudah diberi garis atau gambar yang diinginkan. 
2. Tancapkan stop kontak pada sumber arus listrik.

3. Hidupkan motor listrik dengan menggerakkan hendel tuas sakelar pada posisi "ON".

4. Dekatkan ujung garis bahan pada pisau gergaji, dan mulailah proses penggergajian sampai selesai menurut alur garis yang sudah ditentukan sebelumnya.

5. Matikan mesin dengan menggerakkan hendel tuas sakelar pada posisi "OFF" dan cabut kabel dari dari stop kontak.

Perawatan yang dilakukan pada mesin potong kayu sangat mudah, perawatannya adalah sebagai berikut:

1. Setiap akan dan setelah selesai digunakan mesin dibersihkan dari serbuk kotoran hasil gergajian

2. Memberi pelumasan pada sistem transmisi pada mesin agar lancar dalam penggunaanya.

\section{Identifikasi Analisis Teknik}

Kecepatan Gergaji

$v=\frac{s}{t}$

(Budianto,2012 : 24)

Dengan :

$s=\operatorname{Jarak}(\mathrm{m})$

$v=\operatorname{kecepatan}(\mathrm{m} / \mathrm{s})$

$t=$ Waktu (s)

\section{Gaya Pisau Gergaji}

$F=\sigma_{g} \times A$

(Shigley, $1983: 40$ )

Dengan :

$\sigma_{g}=$ tegangan geser kayu $\left(\mathrm{Kg} / \mathrm{cm}^{3}\right)$

$F=$ Gaya $(K g)$

$A=$ luas penampang

\section{Daya Rencana Motor Listrik}

$P=F \times v$

(Subagja,2007)

Dengan :

$P=$ Gaya motor listrik $(H p)$

\section{Perancangan Sabuk-V dan Puli}

Pemilihan sabuk ditentukan dengan diagram seperti pada Gambar 2 


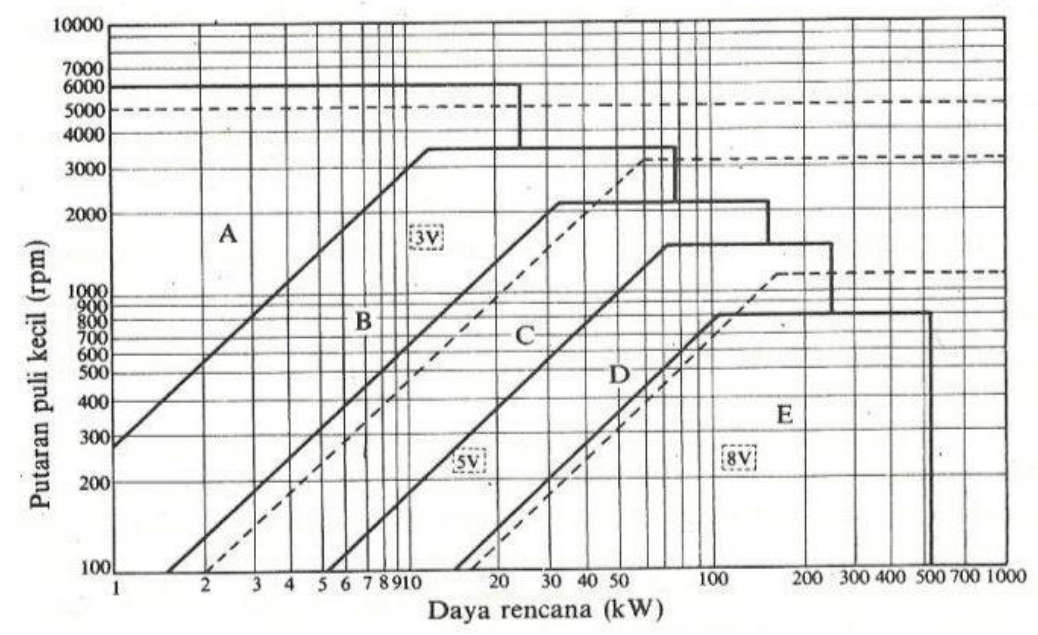

Gambar 2. Pemilihan Sabuk

Perhitungan yang digunakan dalam perancangan sabuk-V antara lain :

1) Momen $(T)$

$T=9,74 \times 10^{5} \frac{P}{n}$

(Sularso dan Kiyokatsu Suga, 2004:7)

Dengan :

$T=$ Momen puntir $(\mathrm{kg} \cdot \mathrm{mm})$

$P=$ Daya rencana $(H p)$

$n=$ Putaran motor (Rpm)

2) Pemilihan tipe sabuk

Pemilihan tipe sabuk berdasarkan Gambar 2 dengan pertimbangan kecepatan putaran $(R p m)$ dan memiliki daya rencana hingga $25 \mathrm{~kW}$.

3) Diameter puli (dk,Dk)

$d_{k}=d_{p}+2 \times 5,5$

$D_{k}=D_{p}+2 \times 5,5$

(Sularso dan Kiyokatsu Suga, 2004:177)

4) Kecepatan sabuk (V)

$V=\frac{\pi \cdot d_{p} \cdot n_{1}}{60 \times 1000}$

(Sularso dan Kiyokatsu Suga, 2004:166)

5) Putaran sabuk $\leq 30 \mathrm{~m} /$ detik,baik

6) Gaya tangensial

$P=\frac{F e . V}{102}$

(Sularso dan Kiyokatsu Suga, 2004:171)

Dengan :

$F_{e}=$ Gaya Tangensial $(N)$ 
7) Panjang keliling ( $\mathrm{L})$

$L=2 C+\frac{\pi}{2}\left(D_{P}+d_{p}\right)+\frac{1}{4 c}\left(D_{P}+d_{p}\right)^{2}$

(Sularso dan Kiyokatsu Suga, 2004:170)

Dengan :

$L=$ Panjang keliling $(\mathrm{mm})$

$c=$ Jarak sumbu poros $(\mathrm{mm})$

$d_{p}=$ Diameter puli kecil $(\mathrm{mm})$

$D_{p}=$ Diameter puli besar $(\mathrm{mm})$

8) Nomor nominal sabuk

9) Jarak sumbu poros (c)

$b=2 L-3,14\left(D_{P}+D_{P}\right)$

(Sularso dan Kiyokatsu Suga, 2004:170)

$c=\frac{b+\sqrt{b^{2}-8\left(D_{p}-d_{p}\right)^{2}}}{8}$

(Sularso dan Kiyokatsu Suga, 2004:170)

10) Sudut kontak $(\theta)$

$\theta=180^{\circ}-\frac{57\left(D_{p}-d_{p}\right)}{c}$

(Sularso dan Kiyokatsu Suga, 2004:173)

11) Jumlah sabuk $N$

\section{Perancangan Poros}

$T=9,74 \times 10^{5} \frac{P}{n}$

(Sularso dan Kiyokatsu Suga, 2004:7)(13)

Dengan :

$T=$ Momen puntir $(\mathrm{kg} / \mathrm{mm})$

$P=$ Daya rencana $(H p)$

$n=$ Putaran poros (Rpm)

Tegangan geser yang diizinkan $\tau_{a}\left(\mathrm{~kg} / \mathrm{mm}^{2}\right)$ umum pada poros dapat diperoleh dengan cara dihitung atas dasar batas kelelahan puntir yang besarnya $40 \%$ dari batas kelelahan tarik yang besarnya kira-kira $45 \%$ dari kekuatan tarik $\sigma_{B}\left(\mathrm{~kg} / \mathrm{mm}^{2}\right)$ sesuai dengan standar ASME. Untuk harga 18\% ini faktor keamanan diambil sebesar 1/0,18 $=5,6$. Harga 5,6 ini diambil untuk bahan SF dengan kekuatan yang dijamin, dan 6,0 untuk bahan $S-C$ dengan pengaruh masa, dan baja paduan. Faktor ini dinyatakan dengan $S f_{1}$.

Selanjutnya perlu ditinjau apakah poros tersebut akan diberi alur pasak atau dibuat bertangga, karena pengaruh konsentrasi tegangan cukup besar. Pengaruh kekasaran permukaan juga harus diperhatikan. Untuk memasukkan pengaruhpengaruh ini dalam perhitungan perlu diambil faktor yang dinyatakan sebagai $s f_{2}$, dengan harga sebesar ,1,3 sampai 3,0

Dari hal-hal di atas maka besarnya $\tau_{a}$ dapat dihitung dengan 
1. $\tau_{\alpha}=\frac{\sigma_{B}}{S f_{1} \times S f_{2}}$

(Sularso dan Kiyokatsu Suga, 2004:8)

Dengan :

$\tau_{\alpha}=$ Tegangan geser yang diizin $-\operatorname{kan}\left(\mathrm{kg} / \mathrm{mm}^{2}\right)$

$\sigma_{B}=$ Kekuatan tarik $\left(\mathrm{kg} / \mathrm{mm}^{2}\right)$

$s f_{1}=$ Faktor keamanan yang tergantung pada jenis bahan

$s f_{2}=$ Faktor keamanan yang tergantung pada bentuk poros

2. $d_{s}=\left[\left(\frac{5,1}{\tau_{\alpha}}\right) \sqrt{\left(K_{m} M\right)^{2}+\left(K_{t} T\right)^{2}}\right]^{\frac{1}{3}}$

(Sularso dan Kiyokatsu Suga, 2004:18)

Dengan :

$d_{s}=$ Diameter poros $(\mathrm{mm})$

$K_{m}=$ Faktor koreksi lentur

$M=$ Momen puntir $\left(\mathrm{kg} / \mathrm{mm}^{2}\right)$

$K_{t}=$ Faktor koreksi puntir

3. $\tau_{\text {hitung }}=\frac{16 T}{\pi \cdot d^{3}}$

(Sularso dan Kiyokatsu Suga, 2004:7)

4. Defleksi pada poros

$\theta=584 \frac{T l}{G d_{s}^{4}}$

(Sularso dan Kiyokatsu Suga, 2004:18)

Dengan :

$\theta=$ Defleksi puntiran $\left(^{\circ}\right)$

$T=$ Momen puntir $\left(\mathrm{kg} / \mathrm{mm}^{2}\right)$

$L=$ Panjang poros $(\mathrm{mm})$

\section{Perencanaan Bantalan}

1. Beban dinamis ekuivalen bantalan gelinding

$F_{e}=\left(X_{r} \cdot V \cdot F_{r}+Y_{a} \cdot F_{a}\right) K s$

(Agustinus Purna Irawan, 2009 : 104)(18)

Dengan :

$V=$ faktor rotasi (1 untuk semua tipe batalan ketika cincin dalam yang berputar)

$K s=$ faktor service

$F_{r}=$ Gaya radial $(N)$

$F_{a}=$ Gaya Aksial $(N)$

2. Umur bantalan

$L=\left[\frac{C}{F_{e}}\right]^{k} \times 10^{6}$

(Agustinus Purna Irawan, 2009 : 104)(19)

Dengan :

$L_{b}=$ Umur pakai bantalan(putaran)

$C=$ Beban dinamis izin $(N)$ 
$F_{e b}=$ Beban dinamis ekuivalen bantalan $(N)$

$k=$ faktor dinamis bantalan (3 untuk bantalan bola)

\section{Perencanaan Rangka}

Perencanaan rangka mesin potong kayu menggunakan analisis dari program software autodesk inventor professional 2014.

\section{Proses Permesinan dan Perakitan}

proses manufaktur dimana objek dibentuk dengan cara membuang atau menghilangkan sebagian material dari benda kerjanya.

\section{Mesin Bubut (Turning)}

Kecepatan Pemakanan (F):

$F=f \cdot n(\mathrm{~mm} /$ menit $)$

(teknik permesinan bubut 1, 2013:123)

Dengan :

$f=$ besar pemakanan atau bergesernya pahat $(\mathrm{mm} / \mathrm{put})$

$n=$ putaran mesin (put/menit)

Waktu Pemesinan $\left(\mathbf{T}_{\mathbf{m}}\right)$

Bubut rata $=\frac{\text { Panjang pembubutan rata }(L) \mathrm{mm}}{\text { Kecepatan Pemakanan }(F) \mathrm{mm} / \text { menit }}$ menit

$t m=\frac{L}{F}$ (menit)

(teknik permesinan bubut 1, 2013:125)

$\mathrm{L}=\ell \mathrm{a}+\ell(\mathrm{mm})$

(teknik permesinan bubut 1, 2013:125)

$\mathrm{F}=\mathrm{f} \cdot \mathrm{n}(\mathrm{mm} /$ putaran $)$

(teknik permesinan bubut 1, 2013:125)

Bubut muka

$L=\frac{d}{2}+l_{a}(\mathrm{~mm})$

(teknik permesinan bubut 1, 2013:125)

\section{Waktu Pengeboran}

$L=\ell+0,3 \cdot d(\mathrm{~mm})$

(teknik permesinan bubut 1, 2013:129)(27)

Dengan :

$d=$ diameter benda kerja

$f=$ pemakanan dalam satu putaran $(\mathrm{mm} /$ putaran $)$

$n=$ putaran benda kerja (Rpm)

$\ell=$ panjang pembubutan muka $(\mathrm{mm})$

$l_{a}=$ jarak star pahat $(\mathrm{mm})$

$L=$ panjang total pembubutan muka $(\mathrm{mm})$

$F=$ kecepatan pemakanan $\operatorname{setiap}(\mathrm{mm} /$ menit $)$ 
Mesin Frais

Panjang Tempuh Alat Potong $(L)$

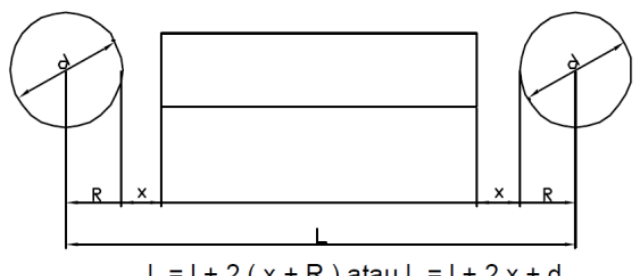

Gambar 3. Panjang Tempuh Alat Potong

waktu pemakanan $(F)$

$T=\frac{L \times i}{f}$

dimana

$F=f \cdot z \cdot n(\mathrm{~mm} /$ putaran $)$

(wirawan sumbodo,et al, 2008,: 304)

Dengan:

$T=$ Waktu pengerjaan

$i=$ Frekuensi pemakanan

$z=$ Jumlah mata potong

\section{Mesin Gurdi}

Untuk Mesin Gurdi jenis gerak makan dilakukan secara manual (Hand-feed Drilling Machine), tidak ada rumus tertentu yang digunakan, karena proses pemakanan dilakukan berdasarkan perkiraan operator mesin.

\section{METODE PERANCANGAN}

Bahan-bahan yang digunakan dalam penelitian ini ditunjukkan dalam Tabel 1 .

Tabel 1. Bahan penelitian

\begin{tabular}{|c|c|c|c|}
\hline No & Nama barang & Data teknik & jumlah \\
\hline 1 & Profil L & ANSI L $1.25 \times 1.25 \times 3.16$ & 2 \\
\hline 2 & Besi Plat & $49 \times 36 \times 5 \mathrm{~mm}$ & 2 \\
\hline 3 & Besi Plat & $36 \times 36 \times 12 \mathrm{~mm}$ & 2 \\
\hline 4 & Besi Plat & $28 \times 28 \times 12 \mathrm{~mm}$ & 2 \\
\hline 5 & Besi Plat & $\varnothing 65 \times 12 \mathrm{~mm}$ & 1 \\
\hline 6 & Besi Plat & $84 \times 36 \times 12 \mathrm{~mm}$ & 1 \\
\hline 7 & Besi Plat & $125 \times 35 \times 12 \mathrm{~mm}$ & 1 \\
\hline 8 & Besi AS & St $\varnothing 1 " X 1 \mathrm{M}$ & 1 \\
\hline 9 & Plywood & $10 \mathrm{~mm}$ & 1 \\
\hline 10 & Bearing & 202 & 2 \\
\hline 11 & Flans Bearing & 202 & 2 \\
\hline 12 & Flans Bearing & 203 & 2 \\
\hline 13 & Reng Per Baja & $\varnothing 10 \mathrm{~mm}$ & 24 \\
\hline 14 & Baut & $M 10 \times 1,25 \times 30$ & 12 \\
\hline 15 & Mur & $\mathrm{M} 10 \times 1,25$ & 12 \\
\hline 16 & Sander & $\varnothing 100 \mathrm{~mm}$ & 1 \\
\hline
\end{tabular}




\begin{tabular}{|c|l|c|c|}
\hline 17 & Amplas & $\varnothing 100 \mathrm{~mm}$ & 1 \\
\hline 18 & Motor & 200 watt & 1 \\
\hline 19 & Sabuk-V & Bando A-24 & 2 \\
\hline 20 & Puli & $1,5 \mathrm{in}$ & 2 \\
\hline 21 & Puli & $3,5 \mathrm{in}$ & 2 \\
\hline 22 & Kawat Las & RD $-26 \varnothing 2 \mathrm{~mm}$ & $1 / 2 \mathrm{~kg}$ \\
\hline 23 & Paku & $\varnothing \mathrm{inch}$ & $1 \mathrm{ons}$ \\
\hline 24 & $\begin{array}{l}\text { Batu Gurinda } \\
\text { Potong }\end{array}$ & 2 \\
\hline 25 & $\begin{array}{l}\text { Batu Gurinda } \\
\text { Datar }\end{array}$ & $\varnothing 4$ “ & 1 \\
\hline 26 & Gergaji & Bosch T101A HSS & 1 \\
\hline 27 & Tiner & Abdunner $600 \mathrm{ml}$ & 1 \\
\hline 28 & Cat Besi & Avian $1 \mathrm{~kg}$ & 1 \\
\hline 29 & Kuas & Prima $1 / 2$ " & 2 \\
\hline
\end{tabular}

Alat-alat yang digunakan dalam penelitian ini, antara lain:

1. Mesin gergaji bolak-balik dan kelengkapan-nya

2. Mesin gerinda manual dan kelengkapannya

3. Mesin gurdi dan kelengkapannya

4. Mesin las SMAW dan kelengkapannya

5. Mesin bubut dan kelengkapannya

6. Mesin frais dan kelengkapannya

7. mesin press dan kelengkapannya

8. Alat ukur dan kelengkapannya

9. Peralatan pertukangan dan kelengkapannya

10. Hand taps $8 \times 1,25$ dan kelengkapannya

11. APD Welding

12. Mata Gerinda potong

13. Mata Gerinda datar

14. APD Permesinan

15. Mata bor $5 \mathrm{~mm}$

16. Mata bor $7 \mathrm{~mm}$

17. Mata bor $9 \mathrm{~mm}$

18. Mata bor $17 \mathrm{~mm}$ 


\section{Diagram Alir Pengerjaan}

Diagram alir pengerjaan mesin potong kayu dapat dilihat dalam Gambar 4.

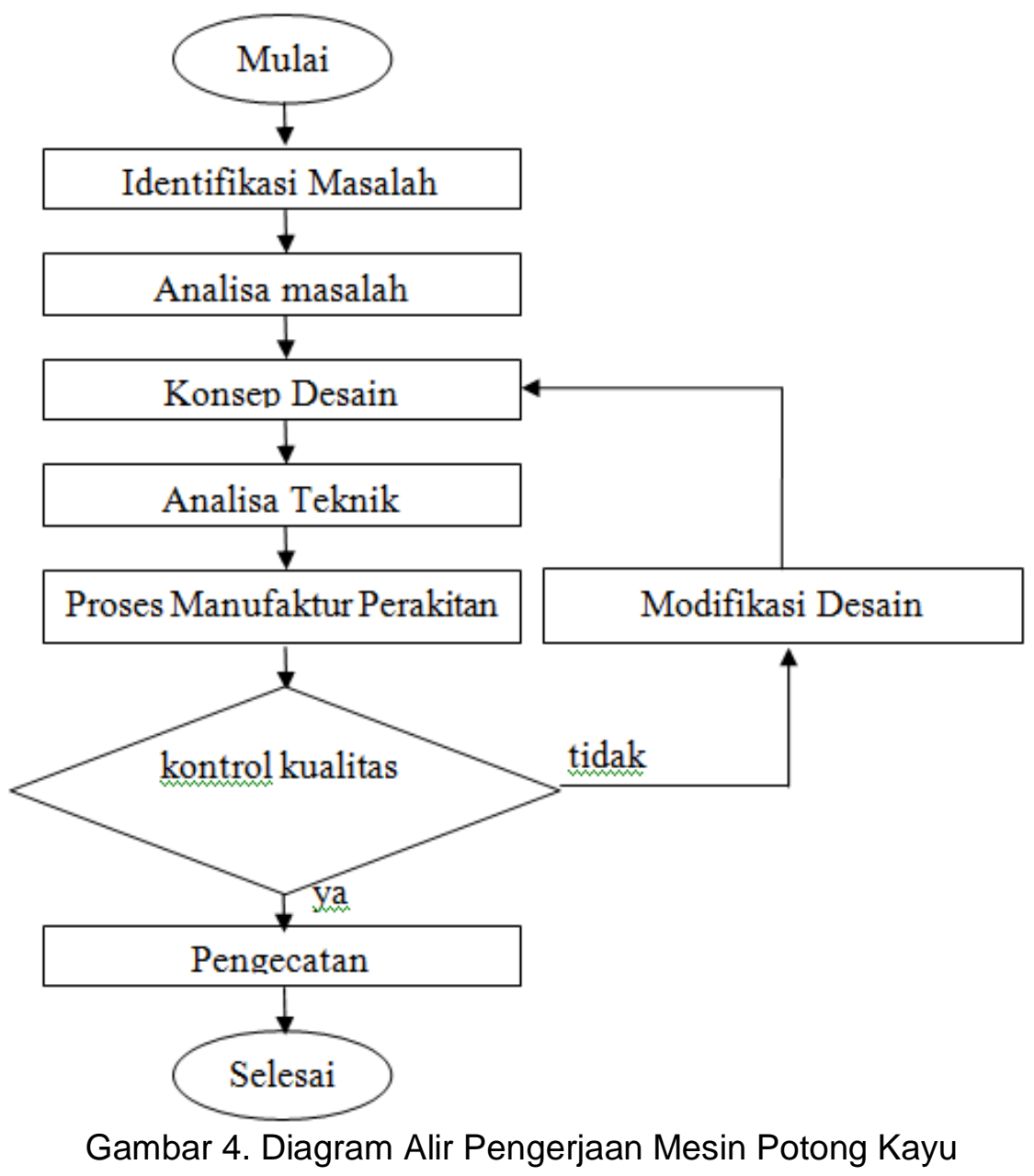

\section{PEMBAHASAN}

\section{a. Perencanaan}

Dari perencanaan dan pembuatan mesin potong kayu menghasilkan mesin yang mampu memotong jenis kayu dengan tegangan geser maksimum $7 \mathrm{~kg} / \mathrm{cm}^{2}$ dan hemat energi dibandingkan mesin sekelasnya karena hanya memerlukan daya sebesar 200 watt, dimensi lebih kecil yaitu $900 \times 350 \times 350 \mathrm{~mm}$, memiliki 2 fungsi yakni memotong dan menghaluskan sebagian permukaan, dan dapat memotong lurus maupun membuat alur.

Mesin potong kayu menggunakan daya motor berkisar 0,016 HP yang mana sudah mencukupi akan daya kerja yang dibutuhkan. Sedangkan daya motor listrik yang ada dipasaran adalah $0,25 \mathrm{HP}$.

Hasil analisis pada transmisi, yaitu transmisi mesin potong kayu menggunakan 2 pasang puli dan sabuk-V dengan perbandingan puli $38,1 \mathrm{~mm}$ dengan $88,9 \mathrm{~mm}$, dengan jarak sumbu poros $220 \mathrm{~mm}$. Hasil putaran dari motor listrik $2800 \mathrm{Rpm}$ oleh transmisi direduksi menjadi $514 \mathrm{Rpm}$. Momen puntir $=T_{1}=86,96 \mathrm{~kg} / \mathrm{mm}, T_{2}=$ $202,91 \mathrm{~kg} / \mathrm{mm}$ dan $T_{3}=473,73 \mathrm{~kg} / \mathrm{mm}$ menggunakan sabuk-V tipe A, kecepatan 
sabuk-V adalah $V_{A}=5,58 \mathrm{~m} /$ detik. dan $V_{B}=2,39 \mathrm{~m} /$ detik. Dari hasil perhitungan putaran sabuk-V lebih rendah dari putaran sabuk maksimum yaitu $V_{A}=5,58 \mathrm{~m} /$ detik $<30 \mathrm{~m} /$ detik dan $V_{B}=2,39 \mathrm{~m} /$ detik $<30 \mathrm{~m} /$ detik berarti baik. Panjang keliling diperhitungkan $L=642,32$, no sabuk 24, faktor koreksi $K \theta=0,96^{\circ}$, besarnya gaya tarik total yang diterima poros transmisi akibat tarikan adalah $F_{A}=11,45 \mathrm{~kg}$, dan poros eksentrik adalah $F_{B}=26,78 \mathrm{~kg}$. jumlah sabuk yang digunakan 2 buah, serta jarak sumbu poros $220_{-20}^{+25} \mathrm{~mm}$

Poros pada mesin potong kayu meneruskan daya dari motor listrik sebesar $0,25 \mathrm{Hp}$. Poros transmisi berputar $1200 \mathrm{Rpm}$ dan poros eksentrik berputar $514 \mathrm{Rpm}$ dari hasil reduksi transmisi mesin potong kayu. Momen puntir yang dihasilkan poros transmisi adalah 202,92 $\mathrm{kg} . \mathrm{mm}$ dan poros eksentrik adalah $189,50 \mathrm{~kg} . \mathrm{mm}$. Perencanaan poros menggunakan bahan St 37 dengan kekuatan tarik $37 \mathrm{~kg} / \mathrm{mm}^{2}$. Dengan faktor koreksi $S f_{1}=6,0$ dan $S f_{2}=3,0$ tegangan yang diijinkan pada poros $\sigma_{a}=2,09 \mathrm{~kg} / \mathrm{mm}^{2}$. Pada poros transmisi digunakan faktor $K_{m}=1,0$ dan faktor $K_{t}=$ 1,5,dan Poros eksentrik digunakan faktor $K_{m}=2,0$ dan faktor $K_{t}=2,0$ sehingga didapat diameter poros transmisi $=13 \mathrm{~mm}$, dan poros $B=10 \mathrm{~mm}$. Pada mesin potong kayu poros transmisi diameter terkecilnya $17 \mathrm{~mm}$ dan poros eksentrik diameter terkecilnya $15 \mathrm{~mm}$ karena menyesuaikan besarnya bantalan yang ada di pasaran, yaitu $17 \mathrm{~mm}$ dan $15 \mathrm{~mm}$. Tegangan yang terjadi pada poros transmisi sebesar $0,5 \mathrm{~kg} / \mathrm{mm}^{2}$, dan pada poros eksentrik sebesar $0,72 \mathrm{~kg} / \mathrm{mm}^{2}$ jadi poros aman digunakan dikarenakan thitung $\leq$ iijin yaitu $0,5 \mathrm{~kg} / \mathrm{mm}^{2} \leq 2.05 \mathrm{~kg} / \mathrm{mm}^{2}$ dan $0,72 \mathrm{~kg} / \mathrm{mm}^{2} \leq 2.05 \mathrm{~kg} / \mathrm{mm}^{2}$.

Rangka pada mesin potong kayu menggunakan bahan mild steel dengan yield strength $207 \mathrm{Mpa}$. Beban yang ada pada motor listrik sebesar $3 \mathrm{~kg}$. Tegangan yang terjadi pada rangka mesin jig saw adalah 5,942 Mpa $\leq$ yield strength 207 Mpa maka rangka aman digunakan.

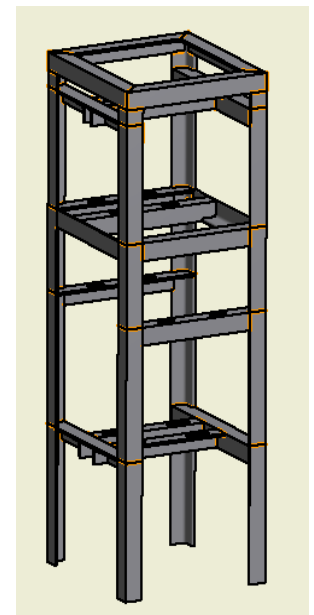

Gambar 5. Rangka Mesin Potong Kayu

\section{b. Pembuatan}

Proses manufaktur dan perakitan pembuatan mesin potong kayu meliputi pengerjaan bubut, frais, tabs, gurdi dan las memakan waktu selama 654,36 menit atau $\pm 10,9$ jam. Mesin potong kayu mampu memotong plywood dengan ketebalan $2 \mathrm{~cm}$ dan dapat membuat alur. Pengecatan mesin potong kayu menggunakan cat kayu dan besi berwarna hijau. 


\section{KESIMPULAN}

Dari hasil proses perancangan dan pembuatan mesin potong kayu dapat disimpulkan, yaitu:

1. Dimensi mesin potong kayu $900 \times 350 \times 350 \mathrm{~mm}$.

2. Gergaji yang digunakan pada mesin potong kayu berbentuk lurus dengan panjang $120 \mathrm{~mm}$, tebal $2 \mathrm{~mm}$ dan gerak gergaji vertikal bolak-balik sepanjang $30 \mathrm{~mm}$.

3. Sistem transmisi menggunakan prinsip poros eksentrik yaitu dengan lingkaran eksentrik. Lingkaran eksentrik berfungsi mengubah gerak melingkar menjadi gerak bolak-balik. Menggunakan 4 puli (1,5" dan 3,5") dan sabuk-V jenis A 24 untuk mengubah putaran motor listrik $2800 \mathrm{Rpm}$ menjadi $514 \mathrm{Rpm}$.

4. Mesin potong kayu menggunakan daya motor 0,25 Hp atau 200 watt.

5. Tingkat keamanan pada mesin potong kayu setelah dilakukan perhitungan teoritis mulai dari sistem transmisi, poros, dan rangka yaitu kecepatan sabuk $A=5,58 \mathrm{~m} /$ detik dan $B=2,39 \mathrm{~m} /$ detik $\leq 30 \mathrm{~m} /$ detik. Defleksi yang terjadi pada poros transmisi sebesar $0,4^{\circ}$ dan poros eksentrik sebesar $0,061^{\circ}$ dinyatakan aman karena kurang dari defleksi izin yaitu $0,25^{\circ}$ dan pada rangka mesin potong kayu hasil tegangan lebih kecil dari yield strength material sebesar 5,942 $\mathrm{MPa} \leq 207 \mathrm{MPa}$ dengan defleksi 0,003 $\mathrm{mm}$.

6. Proses manufaktur dan perakitan mesin potong kayu setelah dilakukan perhitungan teoritis mulai dari bubut, frais, tabs, gurdi dan las memakan waktu 564,34 menit atau $\pm 10,9$ jam.

7. Gambar kerja modifikasi konstruksi mesin potong kayu digunakan untuk proses pembuatan mesin yang terdapat dalam lampiran. 


\section{DAFTAR PUSTAKA}

Budianto. 2012. Proses Perancangan Mesin Jig Saw.Tugas Akhir, Universitas Negeri Yogyakarta.

Direktorat Pembinaan Sekolah Menengah Kejuruan Direktorat Jenderal Pendidikan Menengah Kementerian Pendidikan Dan Kebudayaan. 2013 Teknik Pemesinan Bubut 1. Cimahi.

Isma Putra Boy, Hidayat Alfan, Jaka, 2008, Elemen Mesin Teknik Industri, Graha Ilmu, Yogyakarta.

Shigley, E. Josep dan Mitchell, D. Larry. 1984. Perencanaan Teknik Mesin. Jakarta: Erlangga.

Subagja. 2007. Sains Fisika Sma. Jakarta: Bumi Aksara.

Sularso, Ir., Suga, Kiyokatsu. 2002. Dasar Perencanaan Dan Pemilihan Elemen Mesin. Jakarta. Pt. Paradnya Paramita.

Wirawan Sumbodo dkk, 2008. Teknik Produksi Mesin Industri jilid II. Direktorat Pembinaan Sekolah Menengah Kejuruan. Direktirat Jendral Manajemen Pendidikan Dasar dan Menengah, Departemen Pendidikan Nasional. 